\title{
Neurodevelopmental outcome of high risk newborns discharged from special care baby units in a rural district in India
}

\author{
Nandita Chattopadhyay, ${ }^{1}$ Kaninika Mitra² \\ ${ }^{1}$ Department of Paediatrics, IQ City Medical College, Durgapur, WB; ${ }^{2}$ UNICEF, Kolkata, India
}

\begin{abstract}
Significance for public health
The public health significance of this study lies in the fact that a large proportion of high-risk newborns in rural India were detected with developmental delay and some preventable perinatal and neonatal factors like prematurity, low birth weight, sepsis and meningitis were found to be associated with the problem. So, it suggests that prevention of these perinatal factors, timely detection with proper screening methods and early intervention will help curb the burden of disability in the community. Once a disability develops in a child, the magnitude of the problem swells in all aspects: medical, social and economic. But much of this burden can be lessened if we intervene early, as a third of most disabilities are preventable. Moreover, if we can identify the perinatal factors leading to neonatal brain damage and prevent them, much of the neuro-developmental delay can be averted.
\end{abstract}

\section{Abstract}

Background. High risk newborns are most vulnerable to develop neuro-developmental delay (NDD). Early detection of delay in this group and identification of associated perinatal factors and their prevention can prevent disability in later life.

Design and methods. Observational cohort study. Field based tracking and neuro-developmental screening of high risk newborns discharged between January 2010 to June 2012 from a district Hospital in India was conducted by a team of developmental specialists, using standardized tools like Denver Developmental Screening Tool II, Trivandrum Developmental Screening Chart and Amiel-Tison method of tone assessment. Associated perinatal factors were identified. Early intervention was initiated on those detected with NDD.

Results. Developmental delay was detected in $31.6 \%$ of study population. Prevalence of NDD was significantly higher in low birth weight (LBW, $>2 \mathrm{~kg}$ ), preterm ( $<36$ weeks) and twins. Neonatal sepsis/meningitis and convulsions also showed significant association with NDD. Of the 134 with developmental delay, 61 were preterm, $80 \mathrm{LBW}$, with h/o sepsis in 52, convulsion in 14, birth asphyxia in 39 and jaundice in 14 neonates.

Conclusions. Incidence of NDD among high risk newborns is significantly high with LBW, prematurity and neonatal illnesses are major contributors. Most NDDs go undetected in the early years of life. Improved perinatal care, early detection and early intervention at the grass root level will bring down incidence of developmental challenges in this vulnerable group.

\section{Introduction}

Every newborn baby has to go through a complex process of growth and development at various levels to ultimately emerge as a normal adult. Any deviation in these stages of development will lead to devel- opmental disability. Such disability may express in various forms, which include mental retardation, cerebral palsy, autism, attention deficit disorders, visual and hearing problems, speech and language disorders, learning disabilities and many more.

Developmental challenge in children is an emerging problem across the globe, which is largely associated with improved neonatal survival. ${ }^{1}$ Improved newborn care is leading to salvage of many critically ill newborns, but many of them survive with brain damage, leading to ultimate developmental disability. Sick neonates, particularly preterm babies, very low birth weight (VLBW) and extremely low birth weight (ELBW) babies (birth weights less than 1500 and $1000 \mathrm{~g}$ respectively) with perinatal hypoxia and hypoxic-ischaemic encephalopathy, sepsis, severe jaundice etc. are most vulnerable to poor neuro-developmental outcome. ${ }^{2}$ Insult to the developing brain may lead to gross and fine structural changes resulting in smaller brain size, reduced white and grey matter, ventriculomegaly, decreased callosal projections and altered fibre tract organization, which eventually affects neural function. ${ }^{3}$ Hence, a close neurodevelopmental follow-up of these high-risk newborns is essential for early detection of any brain damage, to prevent or restrict a poor neurodevelopmental outcome through early intervention.

Intrauterine and neonatal insults substantially affect the global burden of disease, measured in disability-adjusted life-years, because they contribute to both premature mortality and long-term disability. ${ }^{4}$ However, little is known about the severity and distribution of longterm impairments after intrauterine or neonatal insults. As a result, sequelae from intrauterine and neonatal insults have not been adequately captured in estimates of the global burden of disease. ${ }^{5,6}$

Though perinatal and newborn care is improving in rural India, a section of the rural population is still deprived of all the available facilities, due to socio-economic, cultural and topographical reasons. There is very scanty data from this part of the globe, regarding neuro-developmental outcome of high risk newborns and the magnitude of the problem of evolving developmental challenges, hence we remain oblivious of the gravity of the situation.

Recognition of precipitating factors and adequate preventive measures, detection of early markers of developmental delay and early intervention measures can go a long way in preventing childhood disability. ${ }^{7}$ This calls in for a neuro-developmental follow-up of high risk babies by a specialized team, using proper scientific methodology. ${ }^{8}$

With this background, we ventured to follow up high risk babies discharged from the District Newborn Care unit at Purulia, a remote, tribal district of West Bengal, India to study the prevalence of delayed development in high risk babies and identify their various aetiological factors and associations. Simultaneous provision of early intervention was also initiated as a preventive and therapeutic measure.

\section{Objectives of the study}

The aims of this paper are: i) to assess the neuro-developmental outcome of high-risk newborns discharged from the Special Care baby Unit in Purulia District hospital, during the period January 2010 - June 
2012 ; ii) to identify the factors associated with neuro-developmental delay in the study population.

\section{Design and methods}

Our study population included all Special Neonatal Care Unit (SNCU) graduates from the district Hospital, Purulia (India) from January 2010 to June 2012. Babies from families which had migrated elsewhere from the district were excluded.

A meticulous door to door tracking was performed by a group of local health workers in all 20 blocks of the district. The target population was thus tracked and categorized according to their home address and any death among them was also noted. This cohort hailed from a remote rural area where most parents were petty farmers or unskilled labourers. The parents were motivated to attend a screening program organized at the District Headquarters, which was conducted in October, 2012, by a group of trained Developmental Specialists led by a developmental Paediatrician.

The neuro-developmental screening process involved procurement of detailed clinical profile including full perinatal history, demographic and socio-economic profile through a structured questionnaire. Anthropometry was done using an electronic weighing scale, an infantometer (for children up to 2 yrs) and stadeometer ( 2 yrs and above) and measuring tape to record weight, length or height, mid-arm circumference (MAC) and head circumference. General examination, a brief neurological examination and neuro-motor assessment by Amiel Tyson Method, ${ }^{9}$ were conducted by the paediatrician, passive tone assessment was also done, which also was quite informative. ${ }^{10}$

Developmental screening was performed using the following tools: i) TDSC (Trivandrum Developmental Screening Chart) in children up to 2 years of age: this is a simple screening tool with 17 items covering the motor, cognitive and language domains of development, based on Bailley developmental screening tool, developed and validated in India. ii) DDST II (Denver Developmental Screening Tool II) for children $>2$ years of age: an internationally accepted and widely used screening tool covering the 4 domains of gross motor, fine motor-adaptive, personalsocial and language. iii) Visual fixation and tracking assessed, followed by eye check-up with fundoscopy done by an ophthalmologist, for children with visual problems. iv) Hearing assessment in children above 1 year was done with a paediatric audiometer.
Any child screened as delayed by the screening tools or showing visual or hearing impairment or having speech delay was considered as having developmental delay.

\section{Results}

Analysis of study population revealed the following basic data: 717 babies were discharged over the study period, out of whom our field workers could trace 634 children (88.4\%), of whom, 562 were alive, while 72 had expired (11.3\%). Out of these 562,427 children attended the screening camp (75.9\% of identified children), while 135 children did not turn up for the screening, possibly due to the remoteness of their villages and difficulty in transportation. Lack of health awareness was also a contributing factor. On screening 427 children, 134 were found to have some developmental delay/challenge (31.6\% prevalence).

\section{Profile of study population $(n=427)$}

Sex distribution: male: 269 (62.9\%); female: 158 (37.1\%).

Age distribution: 0-6 mo: 38 (8.8\%), >6-12 mo: 71 (16.6\%), >12-18 mo: 89 (20.8\%), >18-24 mo: 81 (18.9\%), >24 mo: 147 (34.4\%)

Gestation: 158 (39.3\%) were preterm (<37 weeks gestation) and 244 (60.7\%) were term (37weeks or more) babies. Gestation at birth of 25 babies was not recorded.

Birth weight: 86 had a birth weight less than $2.5 \mathrm{~kg}$ and of them 41 were less than $1.5 \mathrm{~kg}$ (VLBW).

Twins: 28 were twins, representing 14 twin pregnancies out of 413 pregnancies, i.e., $3.3 \%$ twin births reported.

Neonatal illnesses: birth asphyxia in 124 (29\%), sepsis and pneumonia in $189(44.2 \%)$, jaundice in $67(15.6 \%)$ babies. Other problems were noted in 45 (10.5\%) babies.

Records of hypoglycaemia was not available, though 30 babies presented with a history of neonatal seizures without definite history of sepsis, which may be due to hypoglycaemia. Demographic characteristics are presented in Table 1.

More than one third (34.2\%) of the study population were in the age group of more than 24 months, followed by $20.8 \%$ in the $12-18$ month age group. Though overall incidence of developmental delay did not differ significantly among the various age groups $(\mathrm{P}>0.05)$, maximum incidence of developmental delay was detected in the age group of 1218 months, which differed statistically from those with normal

Table 1. Distribution and developmental outcome by demographic characteristics.

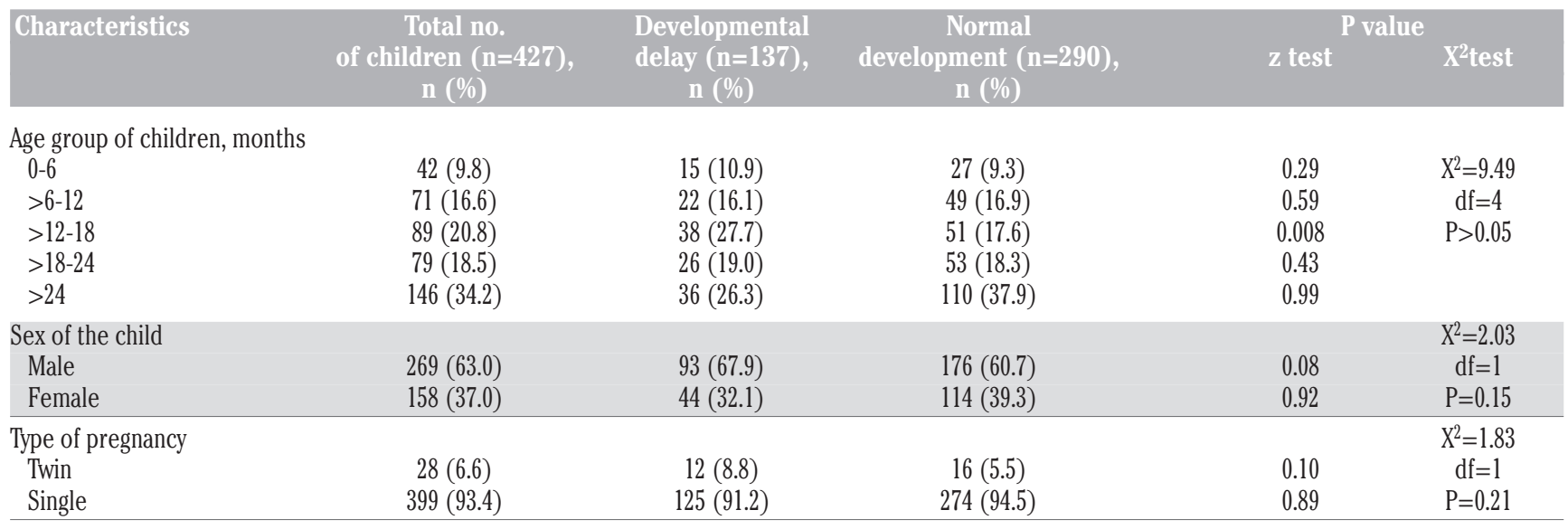

P value of $<0.05$ considered significant 
developPment in the same age group $(\mathrm{P}=0.008)$. Developmental outcome in relation to LBW and gestational age is presented in Table 2.

Prevalence of developmental delay was higher among twins (42.8\%) than in singletons. Out of 12 twin sibs 6 had motor delay, 2 had hearing impairment, 3 had speech delay and 2 had global developmental delay (GDD).

In our study no significant difference in incidence was noted in babies with documented birth asphyxia. Of the 19 babies with cerebral palsy, only 6 gave a history of birth asphyxia.

Of the 427 babies screened 189 gave a history of sepsis but discharge documents did not state whether they were clinical suspects of probable sepsis or culture proven ones. Three had definite history of meningitis. In the cases of 30 babies there was definite mention of convulsions during hospital stay, without evidence of sepsis. It may be presumed that these were cases of metabolic alterations, most likely hypoglycaemia. In the group with sepsis, incidence of developmental delay showed no difference from the general population. In the group with seizures, $46.6 \%$ (14 out of 30 ) babies had some developmental delay, while all 3 babies with meningitis were also affected. Eleven out of 14 with seizures and 3 out of 3 with meningitis had motor delays. This points to the fact that insult to the neonatal brain in the form of infections or metabolic derangement may be detrimental to development.

Of the 134 with developmental delay, 62 were preterm, 80 LBW, 52 had sepsis, 14 had convulsion, 39 birth asphyxia, 14 had jaundice.
Many children presented with more than one developmental challenge whereas many gave history of more than one neonatal illness, so a direct association of the developmental challenge with an aetiological factor was difficult to deduce. Table 3 shows the distribution obtained.

A significant correlation with neonatal seizures and meningitis with developmental delay in later life was evident from this study. Birth asphyxia per se without evidence of encephalopathy with seizures did not show any significant relation with developmental delay.

Incidence of prematurity was significantly higher in children with speech delay $(\mathrm{P}<0.05)$.

Speech delay was associated with cerebral palsy in 7 cases, with GDD in 3 cases and with mild motor delay in 2 cases. Isolated speech delay was found in 27 children, of whom hearing impairment was detected in only 4 cases, possibly due to inadequate screening equipment.

Squint was noted in 8 children and nystagmus was found in 2 children with visual impairment.

Of the 11 children with visual impairment, 10 were preterm babies but only 2 were considered to be definite sequelae of ROP. Visual Impairment became more evident with increase in age.

Many children had delay in more than one domain. Motor delay and cerebral palsy together account for $51.4 \%$ of the developmental challenges detected.

The age-wise presentation of different problems is depicted in

Table 2. Developmental outcome in relation to low birth weight and gestational age.

\begin{tabular}{|c|c|c|c|c|c|}
\hline Characteristics & $\begin{array}{c}\text { Total no. of } \\
\text { children }(\mathrm{n}=387), \\
\text { n }(\%)\end{array}$ & $\begin{array}{l}\text { Developmental } \\
\text { delay }(\mathrm{n}=118), \\
\mathrm{n}(\%)\end{array}$ & $\begin{array}{c}\text { Normal } \\
\text { development }(\mathrm{n}=269) \text {, } \\
\mathrm{n}(\%)\end{array}$ & P value & OR $(95 \% \mathrm{Cl})$ \\
\hline \multicolumn{6}{|l|}{ Birth weight } \\
\hline Low birth weight $(<2.5 \mathrm{~kg})$ & $206(53.2)$ & $80(67.8)$ & $126(46.8)$ & $X^{2}=14.47$ & \\
\hline Normal $(\geq 2.5 \mathrm{~kg})$ & $181(46.8)$ & $38(32.2)$ & $143(53.2)$ & $\mathrm{P}=0.00014$ & $2.39(1.51-3.76)$ \\
\hline \multicolumn{6}{|l|}{ Gestational age at birth } \\
\hline Term (37 weeks and above) & $244(60.7)$ & $61(49.6)$ & $183(65.6)$ & $X^{2}=14.6$ & \\
\hline Preterm (less than 37 weeks) & $158(39.3)$ & $62(50.4)$ & $96(34.4)$ & $\mathrm{P}=0.002$ & $1.94(1.26-2.98)$ \\
\hline
\end{tabular}

Birth weight was not available in 40 infants, of which 21 had normal development while 19 had developmental delay. In the present study, Low birth Weight (LBW) was recorded amongst 206(53.2\%). 67.8\% LBW babies had developmental delay which differed significantly from the normally developing group ( $\mathrm{P}=0.00014) \mathrm{LBW}$ babies had more than twice the risk for developmental delay than normal birth weight children (OR 2.39 with 95\% CI 1.51-3.76) Gestational age could not be recorded in 25 infants, of which 11 had normal development and 14 had developmental delay. 39.3\% of children had preterm birth. More than half (50.4\%) of preterm had developmental delay which differed significantly from children with normal development $(\mathrm{P}=0.002)$. Preterm children had almost twice the risk of developmental delay than those born at term $(\mathrm{OR} 1.94$ with $95 \% \mathrm{CI}$ (1.26-2.98).

Table 3. Distribution of number of Special Neonates Care Unit graduates suffering from different neonatal illnesses by different developmental challenges (total children: 427; normal development: 293; developmental delay: 134).

\begin{tabular}{|c|c|c|c|c|c|c|c|c|c|c|}
\hline \multirow[t]{2}{*}{ Problems } & \multicolumn{8}{|c|}{ Developmental delay, n (\%) } & \multirow{2}{*}{$\begin{array}{l}\text { Normal dev., } \\
\text { n (\%) }\end{array}$} & \multirow[t]{2}{*}{ P value } \\
\hline & $\begin{array}{l}\text { Motor } \\
\text { delay }\end{array}$ & $\begin{array}{c}\text { Tone } \\
\text { abnormality }\end{array}$ & $\begin{array}{c}\text { Cerebral } \\
\text { palsy }\end{array}$ & $\begin{array}{l}\text { Hearing } \\
\text { impairment }\end{array}$ & $\begin{array}{c}\text { Visual } \\
\text { impairment }\end{array}$ & $\begin{array}{l}\text { Speech } \\
\text { delay }\end{array}$ & $\begin{array}{c}\text { Global } \\
\text { development }\end{array}$ & Total & & \\
\hline Sepsis and pneumonia & $21(38.2)$ & $7(26.9)$ & $10(52.6)$ & $1(14.3)$ & $4(36.4)$ & $10(27.8)$ & $9(45.0)$ & $52(38.8)$ & $137(46.7)$ & 0.06 \\
\hline Meningitis & - & - & $1(5.3)$ & - & - & $3(8.3)$ & $1(5.0)$ & $3(2.2)$ & 0 & - \\
\hline Convulsion & $5(9.1)$ & $1(3.8)$ & $5(26.3)$ & - & $1(9.1)$ & $2(5.6)$ & $5(25.0)$ & $14(10.2)$ & $16(5.5)$ & 0.03 \\
\hline Birth asphyxia & $12(21.8)$ & $4(15.4)$ & $6(31.6)$ & $3(42.9)$ & $2(18.2)$ & $9(25.0)$ & $4(20.0)$ & $39(29.1)$ & $85(29)$ & 0.98 \\
\hline Severe jaundice & $3(5.5)$ & $5(19.2)$ & $5(26.3)$ & $1(14.3)$ & $4(36.4)$ & $5(13.9)$ & $2(10.0)$ & $14(10.4)$ & $51(17.6)$ & 0.032 \\
\hline Respiratory disease & $1(1.8)$ & - & - & $1(14.3)$ & - & $2(5.6)$ & $1(5.0)$ & $4(2.9)$ & $12(4.1)$ & 0.29 \\
\hline Congenital anomalies & $2(3.6)$ & - & - & - & - & - & - & $2(1.5)$ & $2(0.7)$ & - \\
\hline Others & $3(5.7)$ & $2(7.7)$ & $2(10.5)$ & $1(14.3)$ & $1(9.1)$ & $4(11.1)$ & $2(10.0)$ & $11(8)$ & $30(10.3)$ & 0.25 \\
\hline Total & 52 & 26 & 19 & 7 & 11 & 35 & 20 & 134 & 293 & - \\
\hline
\end{tabular}

Pvalue $<0.05$ is considered as significant. 
Figure 1. Mild delay and tone abnormality show a decreasing trend with age, whereas cerebral palsy (CP), visual impairment, speech delay and GDD show an increasing trend.

Tone abnormality, with or without motor delay was more marked in the earlier months of life. Most of the cases of CP were evident after 1 year of age It is evident that younger children, up to 18 months of age presented more with only tone abnormalities or slight delays in attaining motor milestones, whereas those above 18 months presented with features of cerebral palsy. It may be presumed that the former group were in a stage of evolving cerebral palsy.

\section{Discussion}

The prevalence of developmental delay among SNCU graduates is found to be quite high (31.6\%), which is similar to the $29 \%$ incidence reported by Calame et al. ${ }^{11}$ A systematic review of 153 studies across the globe, documenting 22,161 survivors of intrauterine or neonatal insults showed an overall median risk of at least one sequelae in any domain as $39.4 \%{ }^{7}$

In our study population we have noticed a sex predilection with a male preponderance which is also reflected in the children identified with developmental delay. The total number of neonates admitted at SNCU in Purulia from January 2010 to December 2012 was 987, among them 640 (64.8\%) were male and 347 (35.2\%) were female. Out of the 562 who were tracked, 359 (63.8\%) were male and $203(36.2 \%)$ were female, showing a similar distribution as recorded at admission. Again, of the 427 who ultimately attended the screening camp-269 were male and 158 female, representing $62.9 \%$ and $37.1 \%$ respectively of the total. The sex distribution among the children with developmental delay showed $67.9 \%$ male and $32.1 \%$ female, suggesting a male predominance, but the ratio does not vary significantly from that of the general study population. The difference in care seeking for male and female newborns and children probably shows the gender-bias prevalent among the families, who are more concerned about the survival and wellbeing of male off-springs than the females, rather than an actual difference in neuro-developmental outcome among male and female babies.

Highest incidence of developmental delay was detected in the age group of 12-18 months (42.6\%). In this younger age group, the findings are subtle and early Intervention will prove more effective than in older children where the problems are more extensive and dense.

In this study, low birth weight and prematurity were found to be the major contributory factors for neuro-developmental delay. Maximum incidence of developmental delay was noted in babies with BW between

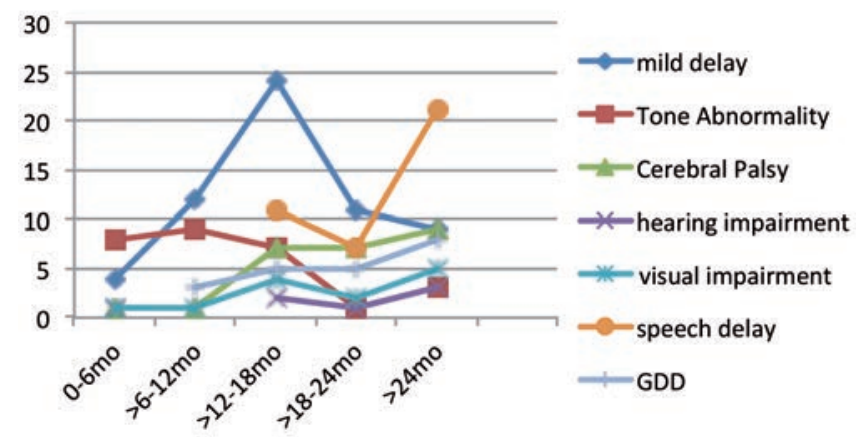

Figure 1. Age wise distribution of various developmental challenges.
$1.5-2.0 \mathrm{~kg}(42.6 \%)$, with a sharp decline in incidence in babies weighing $>2.5 \mathrm{~kg}(19.4 \%)$ at birth.

Incidence of developmental delay is also significantly higher in preterm babies, (37.3\%) than in term babies (23\%), which is supported by a review of 100 related articles by Tao Xiong. ${ }^{2}$ Improvement of gestational age at birth and birth weight will help in curbing the incidence of developmental delay.

Twin babies were found to be more prone to developmental delay than singletons. It was also noted that among the 28 twins birth-weight was less than $2 \mathrm{~kg}$ in 16 babies, $2-2.5 \mathrm{~kg}$ in 5 and more than $2.5 \mathrm{~kg}$ documented in only one baby. Similarly, 20 babies were found to be born below 36 weeks of gestation and only 2 at a gestation above 36 weeks. Birth weight and gestation values were not available for 6 children. Hence, probably this higher incidence of developmental delay is primarily related to LBW and prematurity, rather than being attributable to twin pregnancy. World literature suggests that twin pregnancy, per se, has minimal contributory role in hindering neuro-development. ${ }^{12}$ Studies from Australia have mentioned an incidence of cerebral palsy in twins as 7.1/1000 live births, in contrast to $1.4 / 1000$ in singletons. Speech delay is mentioned to be the major developmental delay in twins born at term. ${ }^{13}$

In our study we could not demonstrate neonatal sepsis or birth asphyxia as significant contributing factors for developmental delay. In this retrospective study we were unable to procure adequate data to substantiate a definite diagnosis of birth asphyxia in many cases and the parental history was inadequate, hence the conclusion needs further verification. Anyhow, the recent literature does focus on the fact that birth asphyxia in term babies may not be a major indicator of neuro-developmental delay in later life. ${ }^{14-17}$

Neonatal seizures showed significant correlation with developmental challenges in our study group, specially motor delays. As we had to often depend solely on scanty discharge notes for evidence, the conclusions need to be further clarified with prospective studies.

In our study, motor delay and cerebral palsy contributed to $51.4 \%$ of all developmental challenges identified, of which motor delay possibly due to evolving cerebral palsy account for $38.5 \%$. This is followed by speech delay in $26.6 \%$ and cognitive delay in $16.9 \%$. Tone abnormalities and motor delay was more common in the first year of life, whereas cerebral palsy became evident in the $2^{\text {nd }}$ year of life. Beyond 2 years of age speech delay and GDD also increased substantially.

The type of developmental delay and its intensity is found to vary with age. At 0-6 months tone abnormality is commonest and in the later part of the $1^{\text {st }}$ year mild delay becomes evident, along-with tone abnormalities. Many of these tone abnormalities are transient and may return to normal tone at a later age, but transient abnormalities of tone in the course of the first year of life has been reported to be associated with ultimate developmental abnormalities in $33.3 \%$ of the cases. ${ }^{15}$

It was interesting to note that out of 134 children screened to have developmental delay, only 4 had been previously diagnosed and were already undergoing treatment. The fact that the rest were not identified earlier indicates the lack of facility for early detection of neuro-developmental delay in this rural setting. This is possibly due to lack of awareness among parents and health care providers as well as nonavailability of a structured health care machinery to address this issue. Early detection and early intervention is the crux of management of developmental challenges and ensuing disability. The level of awareness and availability of required health care facilities need to be looked into through further research.

Studies on neuro-developmental outcome in high risk newborns from resource poor countries are scanty till date. A recent review analysis of 28212 studies, spanning from 1966 to 2011was conducted, of which 153 studies were found suitable for inclusion, to analyse the global burden of long-term consequences of intrauterine and neonatal insults. Unfortunately, only 5 out of 153 studies were from South East Asia. ${ }^{18}$

High risk newborns are not only prone to develop overt developmen- 
tal challenges in the form of cerebral palsy, mental retardation and GDD, visual, hearing and speech defect, but more subtle defects in development may also be the outcome of a stormy neonatal period. Conditions like behavioural problems (ADHD, Autism Spectrum disorder), learning disabilities and scholastic failure may become evident later on , during early school age.

The World Health Organization uses the term disability to refer to a loss of full functional capacity in such domains as mobility, cognition, hearing and vision, which may hinder their full and effective participation in society on an equal basis with others. ${ }^{19}$ In most parts of the world, people with disabilities are subject to multiple deprivations with limited access to basic services, including medical, education, employment, rehabilitation facilities etc. Widespread social stigma plays a major role in hindering their normal social and economic life. According to UN Enable (UN Website particularly developed for disability $)^{20}$ around $10 \%$ of the world's populations, 650 million people, live with disabilities. According to Child Rights Information Network, over 150 million children worldwide have a disability. In India $1.67 \%$ of the $0-19$ population has a disability and $35.29 \%$ of all people living with disabilities are children. Other estimates say that India has 12 million children living with disabilities. About $90 \%$ of children with disabilities worldwide do not attend school. Children with disabilities are at a 1.7 times greater risk of being subjected to some form of violence.

In 2007, estimates published in The Lancet showed that more than 200 million children under the age of five in developing countries fail to reach their full potential. ${ }^{21} \mathrm{~A} 2007$ six-country survey found an incidence of Cerebral Palsy of 2.12-2.45 per 1000 live births..$^{22}$ Recent studies show an average prevalence of CP as 2.5 per 1000 in India. India is home to 25 lakh people with cerebral palsy. The gravity of the problem is largely magnified among the under privileged of our society, where health care facilities are inadequate and the child's health problems are not addressed to unless it is overtly expressive. The British Department for International Development has recognized that disability is a major cause of social exclusion and it is both the cause and consequence of poverty. 18

Hence, any developmental disability is a hindrance for the individual to live with, a burden for the family as well as for the society at large.

\section{Conclusions}

\section{Limitations}

The limitation of this study are: i) the study area being a remote, hilly district, only $66.2 \%$ of the SNCU graduates finally turned up for screening: ii) the discharge notes were often inadequate, hence the perinatal factors like birth asphyxia, sepsis, seizures were not always properly identified and correlation became difficult.

\section{Recommendations}

We would provide the readers the following recommendations: i) a prospective study in future, with structured diagnostic criteria, will yield more authentic results on aetiological analysis. ii) A mechanism for regular follow up of detected cases as well as constant screening of new cases needs to evolve to improve the ultimate outcome and proceed towards intact survival of the SNCU graduates. iii) With early detection of evolving cerebral palsy and other developmental challenges, early intervention will be of great help in preventing disability. ${ }^{23}$ Unfortunately, remoteness and poor communication facilities, coupled with poor resources will pose great hindrance to proper follow-up. Decentralization of Early intervention facilities through District Early Intervention Centres and home-based management have to be focussed on to cater to the needs of this marginalized community.
Correspondence: Nandita Chattopadhyay, 22M Srinath Mukherjee Lane, Kolkata 700030, India.

Tel.: +91.983 .000 .5780 .

E-mail: chattnan@gmail.com

Key words: high-risk newborn, developmental delay, early detection, early intervention.

Acknowledgements: Dr Partha De, Senior Scientist, Indian Statistical Institute, for his help and guidance in data analysis; UDBHAAS Child Development Unit core team for assisting in developmental assessment and early intervention.

Contributions: NC has substantially contributed to conceptualization and designing of study, acquisition, analysis and interpretation of data and drafting and final approval of version to be submitted; KM has significant contribution in concept and design of study, data interpretation and critical revision of the manuscript as well as final approval.

Conflict of interests: the authors declare no potential conflict of interests.

Funding: this paper was funded by UNICEF.

Received for publication: 6 August 2014.

Accepted for publication: 16 December 2014.

(c) Copyright N. Chattopadhyay and K. Mitra, 2015

Licensee PAGEPress, Italy

Journal of Public Health Research 2015;4:318

doi:10.4081/jphr.2015.318

This work is licensed under a Creative Commons Attribution NonCommercial 3.0 License (CC BY-NC 3.0).

\section{References}

1. Fawke J. Neurological outcomes following preterm birth. Semin Fetal Neonatal Med 2007;12:374-82.

2. Nair MKC, Jana AK, Niswade AK. Editorial. Neonatal survival and Beyond. Indian Pediatr 2005;42:985-8.

3. Xiong T, Gonzalez F, Mu DZ. An overview of risk factors for poor neuro-developmental outcome associated with prematurity. World J Paediatr 2012;8:293-300.

4. WHO: The global burden of disease: a comprehensive assessment of mortality and disability from diseases, injuries and risk factors in 1990 and projected to 2020. Cambridge, MA: Harvard University Press, 2001.

5. Olusanya B0. The right stuff: the global burden of disease. PLoS Med 2007;4:e84.

6. Mwaniki MK1, Atieno M, Lawn JE, Newton CR. Long-term neurodevelopmental outcomes after intrauterine and neonatal insults: a systematic review. Lancet 2012;379:445-52.

7. UNICEF. The state of the World's children. Children with disabilities 2013. Available from: http://www.unicef.org/gambia/SOWC_Report_ 2013.pdf

8. Spittle AJ, Orton AJ, Doyle LW, Boyd R. Early developmental intervention programs post hospital discharge to prevent motor and cognitive impairments in preterm infants. Cochrane Database Syst Rev 2007;2:CD005495.

9. Amiel-Tison C. Update of the Amiel-Tison neurologic assessment for the term neonate or at 40 weeks corrected age. Pediatr Neurol 2002;27:196-212.

10. Chaudhari S, Deo B. Neurodevelopmental assessment in the first year with emphasis on evolution of tone. Indian Pediatr 2006; 43:527-34.

11. Calame A, Reymond-Goni I, Maherzi M, et al. Psychological and neurodevelopmental outcome of high risk newborn infants Helv Paediatr Acta 1976;31:287-97. 
12. Goetghebuer T, Ota MO, Kebbeh B, et al. Delay in motor development of twins in Africa: a prospective cohort study. Twin Res 2003;6:279-84.

13. Thorpe K. Twin children's language development. Early Hum Dev 2006;82:387-95.

14. Brouwer SI, van Beijsterveldt TC, Bartels M, et al. Influences on achieving motor milestones: a twin-singleton study. Twin Res Hum Genet 2006;9:424-30.

15. Yudkin PL, Johnson A, Clover LM, Murphy KW. Assessing the contribution of birth asphyxia to cerebral palsy in term singletons. Paediatr Perinatol Epidemiol 1995;9:156-70.

16. Blair E, Stanley FJ. Intrapartum asphyxia: a rare cause of cerebral palsy. J Pediatr 1988;112:515-9.

17. McGregor SG, Cheung YB, Cueto S, et al. Developmental potential in the first 5 years for children in developing countries. Lancet 2007;369:60-9.
18. Department for International Development, UK. Disability, poverty and development. Available from: http://hpod.org/pdf/Disabilitypoverty-and-development.pdf

19. UNESCO. EFA global monitoring report. Available from: http://unesdoc.unesco.org/images/0018/001866/186606E.pdf

20. UN Enable. Facts sheet on persons with disabilities. Available from: http://www.un.org/disabilities/default.asp?id=161

21. Grantham-McGregor Sally, Cheung YB, Cueto S, et al. Developmental potential in the first 5 years for children in developing countries. Lancet 2007;369:60-70.

22. United Cerebral Palsy Research and Education Foundation, US. Infection in the newborn as a cause of cerebral palsy. Available from: http:/ucp.org/

23. Cameron DL, Nixon S, Parnes P, Pidsadny M. Children with disabilities in low-income countries. Paediatr Child Health 2005;10:269-72. 